\title{
TUTORIAL
}

\section{Phonetic documentation of endangered languages: Creating a knowledge- base containing sound recording, transcription and analysis}

\author{
Peri Bhaskararao \\ Research Institute for Languages and Cultures of Asia and Africa, \\ Tokyo University of Foreign Studies, \\ Asahi-cho 3-11-1, Fuchu-shi, Tokyo, 183-8534 Japan
}

Keywords: Acoustic phonetics, Phonetic fieldwork

PACS number: 43.70.Jt [DOI: 10.1250/ast.25.219]

\section{RELEVANCE OF SYSTEMATIC PHONETIC DATA FOR PHONETIC DOCUMENTATION}

Hockett's famous work on modern linguistics [1] divides 'any and every human language' into five subsystems out of which three are central and two are peripheral. According to him, the central subsystems were so designated because 'they have nothing to do, directly, with the nonspeech world in which speaking takes place.' These three subsystems are: the grammatical system, the phonological system and the morphophonemic system. The peripheral subsystems 'impinge both on the nonspeech world and on the central subsystems.' The two peripheral subsystems are: the semantic system and the phonetic system. Hockett further explains that the phonetic system is concerned with 'the ways in which sequences of phonemes are converted into sound waves by the articulation of a speaker, and are decoded from the speech signal by a hearer' and 'the phonetic system touches, in one direction, on the physically analyzable sound waves of the speech signal, but it also touches, in the other direction, on the phonemic system of the language.' He emphasizes that if one wishes to analyze in a systematic way the phonetic subsystem of a language, 'it is necessary first to have a careful description of the most closely related central subsystem' [the phonological subsystem] and 'it is quite futile to try to analyze a phonetic system, either in terms of articulation or acoustically, without knowing about the phonemic system to which it relates.' He cautions that 'acousticians have sometimes attempted the former, and have ended up by making use of an inaccurate, unsystematized conception of the related phonemic system, in place of an accurate and detailed one.'

Phonetic subsystem is the only subsystem of language that has a physical manifestation, viz., speech sounds as its units. Since speech sounds are physical events, they can be recorded, stored, analyzed and retrieved. Acoustics is concerned with the physics of sound. Sounds that 'could' be produced by human organs of speech are a subset of sounds in general (Catford's [2] 'articulatory possibilities of man'). Such articulatory possibilities are very large in number. Out of them, some may never be found in any language as part of its phonological system and some that would be discovered newly might not have been predicted. Hence, instead of enumerating the different articulatory possibilities, one may fruitfully study the actual speech sounds that really occur in the phonological systems of languages. Thus within the subset of 'articulatory possibilities of man,' we have all those sounds that are attested as speech sounds in one or more languages of the world. As Ladefoged [3] originally proposed, "phonetic events that occur in the languages of the world" form part of study of linguistic phonetics. He further clarified that detailed knowledge of the surface phonetic events is essential in developing an adequate phonological theory. To obtain a clear understanding of what constitutes human speech, and to build an adequate phonological theory we need to record and systematize empirical phonetic data from spoken languages. A knowledge-base of linguistic phonetics can be constructed only through empirical observations and analysis of linguistic phonetic events from natural spoken languages. However, many languages are disappearing fast due to endangerment and there is an urgent need to phonetically document these languages.

\section{NEED FOR THE STUDY OF SOUNDS OF ENDANGERED LANGUAGES}

In the context of endangered languages, summarizing his 1991 paper [4], Krauss [5] gives the following figures: 'of the world's 6,000 languages, 20 to $50 \%$ already are or soon will be no longer spoken by children, i.e. are moribund, to become extinct during the 21 st century; at the other end of the scale, only 5 to $10 \%$ (300 to 600) are "safe;" and all 


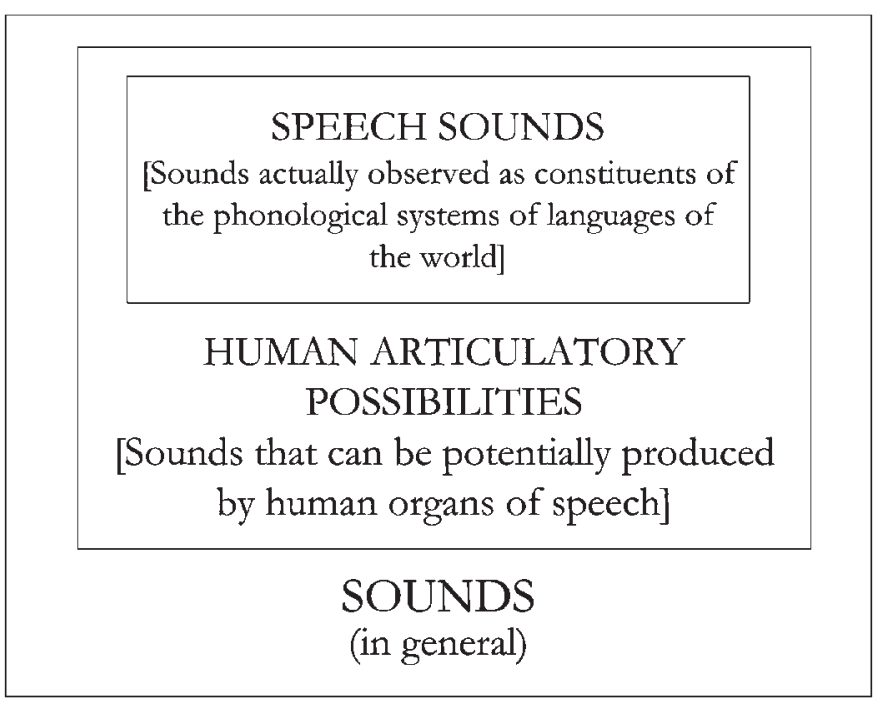

Fig. 1 Speech sounds vs. sounds in general.

the rest, 40 to $75 \%$ are "merely" endangered, may cease being spoken by children during this century.'

There are slightly varying estimates about the total number of languages currently spoken in the world. This is due to the fact that in some cases the demarcation between language and dialect is somewhat difficult and there are some remote corners in the world which may contain some unexplored languages. Irrespective of the total tally of contemporary languages, it is clear that several of them are in the process of disuse and decay which will certainly lead to their demise. Miyaoka [6] emphasizes:

"Many endangered minor languages may have the potential of providing data unobtainable anywhere else that are valuable for issues concerning typology and universality, as well as for historical studies of language and culture. If a language which has no known relatives (e.g., Ainu or Yahgan) becomes extinct without good documentation, the keys to the history and the knowledge of the unique patterns of that language group will be permanently lost."

Ladefoged and Maddieson [7] stress the necessity of recording of the phonetic structures of endangered languages:

"There are about 7,000 languages spoken in the world today; but soon, probably by our great grandchildren's time, only a few hundred may be left. Every language that dies represents a significant loss to human culture, often causing great suffering among those affected. In addition, for those of us who are concerned with the sounds of languages, the disappearance of a language is a loss of a resource for the scientific study of human speech communication. Our notions of what constitutes a possible human language depend on studies of actual human languages."

This loss of speech sounds or groups of speech sounds can happen in two ways: loss due to historical change and loss due to language endangerment and language death. Historical changes in all aspects of language (speech, grammar, semantics etc.) take place in all living languages. Since language is in a constant state of flux, recording of the spoken aspect of a language at a given period of type could result in a 'phonetic snap shot' of the language. The need for such a phonetic snap shot is much more urgent in the case of languages that are currently endangered.

Let us consider the example of Badaga language. Badaga belongs to the Dravidian family and is spoken on the lofty Nilagiri Mountains of South India (along with some other fascinating languages such as Toda and Kota). Emeneau [8] based on his fieldwork around 1935-38, described the nature of two degrees of retroflexion of vowels in Badaga language. He showed a distinction between a simple vowel, its half-retroflexed counterpart, and a fully-retroflexed counterpart. According to him, the half-retroflexed vowels were "produced with edges and tip of the tongue retroflexed or curved upward to approach the alveolar ridge, but without touching or causing friction at any point; the front of the blade of the tongue seems to be raised also in this manner of vowel production." $\mathrm{He}$ described the articulation in fully-retroflexed vowels as follows: "In the vowels with fully-retroflexed resonance the whole tongue is strongly retracted, the edges are curved upwards towards the hard palate well behind the alveolar ridge but without touching or causing friction at any point, and a channel is left in the center of the tongue well visible at the tip in a V-formation." Thus, for instance, this language possessed three types of the vowel [a] distinguished by the presence and degree of concurrent retroflexion. They were $[a],\left[a^{\prime}\right]$, and $\left[a^{\prime \prime}\right]$. The five short vowels (i, e, u, o, a) and the five long vowels ( $\overline{1}, \bar{e}, \bar{u}, \bar{o}, \bar{a}$ ) had two congeners each, giving rise to a total of 30 vowel phonemes. Prof. Emeneau's phonetic observations are very clear and meticulous. However, as he expressed elsewhere [9], he could not make any audio recordings of these sounds because there were no portable tape-recorders in the days of his field work.

However, when in 1991, Prof. Peter Ladefoged and the present author visited the same field area of Badaga language, sufficient phonetic material could not be elicited for making a detailed recording of all the thirty possible vocalic contrasts described by Emeneau. Ladefoged and Maddieson [10] described the situation that we encountered: "Emeneau's fieldwork was conducted in the 1930s, and it seems that the form of Badaga he investigated is no longer spoken. We have made recordings of a large number of Badaga speakers, going from one end of their dialect 
region to another. Our speakers included the son of Emeneau's informant and others from the same district. We found only a few speakers from very conservative groups who maintained a three-way contrast, and then it was in only one or at the most two vowels." However, two speakers did reliably distinguish two sets of words involving the vowel [e:] and [a:] and their two retroflexed congeners. This was a clear case of loss of opportunity to capture the acoustic signal of a fascinating and extensive range of contrasts because these sounds could not be recorded in time. Though fortunately we have Emeneau's clear description of the vowel sounds, we cannot access the original pronunciation material. No known contemporary language makes such a distinction of retroflexion on vowels.

\section{NATURE OF PHONETIC DOCUMENTATION}

The scope of 'Phonetic documentation' includes a systematic collection, classification, analysis and storage of speech sounds of a language. The stored sounds and the analysis should be made accessible for wider use as well as reverification. Even if it is of a very high quality, a simple sound recording of words or longer utterances from a language would not of much later use. For the purpose of a systematic recording of the phonetic material the analyst should first study the phonological pattern of the language under consideration.

Ladefoged [11] succinctly puts it: "There are four basic tasks in making a description of the phonetic structures of a language. First one must decide what to describe; second, suitable speakers must be found; third..., the necessary phonetic data must be recorded and analyzed. Lastly the results must be written up in a coherent whole,... In practice, all these components overlap (especially the writing, which should be carried out through the fieldwork; it should never be left till the investigation is completed)." All these components of linguistic phonetic fieldwork hold good for recording of phonetic structures of endangered languages as Ladefoged and Maddieson [7] state: "Making a record of the phonetic structures of an endangered language is, in principle, no different from making a record of the phonetic structures of any language." A detailed description of the methods of doing linguistic phonetic fieldwork is available in the above two works. The first paper describes the nature and composition of linguistic phonetic structures that are necessary to be looked into before proceeding on fieldwork, including preparation of word lists and other elicitation material before hand. Then the paper discusses about an important point that has to be decided in the field viz., the number and quality of the speakers or language consultants. Since the major concern of that paper was instrumental phonetic techniques,
Ladefoged illustrates various points about the different kinds of instrumentation that need to be carried and utilized in the field. He rightly points out the drawback of doing linguistic phonetic fieldwork without instrumental recording of the material. He shows that instrumental recording of the phonetic material could prove valuable in three ways: possible new interpretation of some phonetic processes, creation of permanent records, and creating a base for quantitative descriptions.

An example of the first possible benefit is drawn from the work on some Tibeto-Burman languages reported in the following publication. Bhaskararao and Ladefoged [12] is based upon fieldwork conducted in India on voiceless nasals in Mizo, Burmese and Angami languages. Our initial auditory observations suggested that the voiceless nasals in Angami are somewhat different from those in the other two languages. When we made and analyzed oral and nasal airflow recordings of these nasals across the three languages, the difference became clear. Figure 2 is a schematic representation of the two types of voiceless nasals that we found. Type B is the case of Angami voiceless nasals. Type $A$ is the case of more 'usual' voicelessness nasals found in other languages like Burmese, Mizo etc. These two types differ in the portion between the time points 2 and 3. In Type A, the 'offset' portion (the portion just before the release of oral closure) contains laryngeal vibration along with nasal airflow. On the other hand, this portion in Type B is characterized by oral and nasal airflow and absence of laryngeal vibration. Though on careful aural observation,

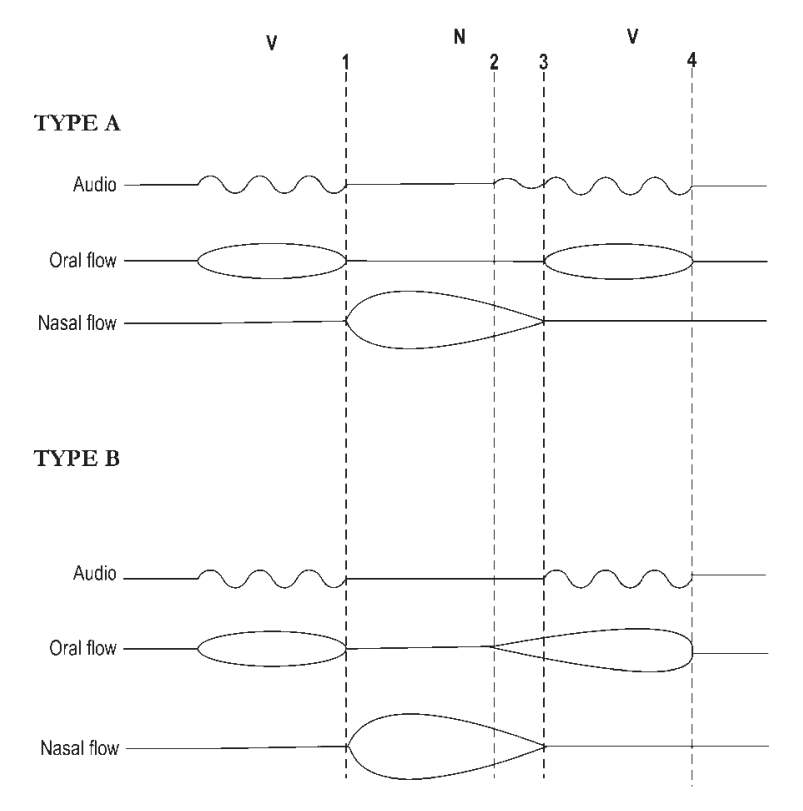

LEGEND: Voicing present $\simeq \quad$ Air flow present $\longrightarrow$ Voicing / Air flow absent Time points (vertical dotted lines) : 1 = nasal begins; $2=$ offset begins; $3=$ nasal ends

Fig. 2 Minute yet significant differences between speech sounds - A case of voiceless nasals. 
we could hear a very fine distinction during this portion between these two sets of languages, the aerodynamic recordings clinched the issue.

There are several research papers and reports that incorporate results of phonetic fieldwork on endangered languages. However, the most significant outcome on the phonetics of endangered languages resulted from an NSF supported project to UCLA for recording the phonetic structures of languages of special phonetic interest that are spoken by limited numbers of speakers. As far as the author can recall, it was the only project of its kind ever undertaken. It had coherent goals, methodology, expertise, instrumentation and support. It was entitled "Phonetic Structures of Endangered Languages" with Peter Ladefoged and Ian Maddieson as the principal investigators. The project, spanning over a period of eight years began in 1991 and involved several phoneticians from around the world for joint field work and analysis. The project rightly felt that: "The survival of many languages is endangered as the speakers die out or are absorbed into larger communities. Soon we will no longer know what these languages sounded like, or what articulatory gestures their speakers used. Their disappearance will result in permanent loss of data for future linguistic investigations." With this background, the project conducted its work and produced significant results. Following a pattern established during the previous research of the principal investigators, the team investigated endangered languages that were important from the linguistic point of view.

It provided standardized descriptions in quantified form using a set of basic phonetic measures, designed to characterize both specific and universal phonetic features. The principal phonetic and phonological patterns were identified and illustrated in specially prepared material, along with supplementary material illustrating coarticulatory and other phonetic phenomena. Both audio and physiological recordings were made. In addition, aerodynamic records for airstream mechanisms and the timing of articulatory gestures, and palatographic records for articulatory contacts were made. Audio recordings were analyzed in the UCLA Phonetics Laboratory. Fully illustrated and documented accounts of the targeted languages were published enabling the knowledge of the sounds and articulatory gestures involved in these endangered languages to remain available for future researchers that could form part of the input to a phonetic knowledge-base.

As publication of the results of analysis is an important component of an ideal project, results of part of the work have been published in a number of research papers [13-39]. Preliminary versions of some of these were initially brought out under the UCLA Working Papers in Phonetics Series (under the title "Fieldwork Studies of Targeted Languages"). The languages investigated in the project include: Aleut, Amis, Apache, Atayal, Avatime, Banawa, Bowiri, Bunun, Cheju, Chickasaw, Dahalo, Defaka, Degema, Gaelic, Hadza, Haida, Iaai, Ilwana, Ingush, Jalapa Mazatec, Khonoma Angami, Montana Salish, Ndumbea, Obulom, Paici, Pirahã, Sandawe, Santrokofi, Tee, Tlingit, Toda, Tsez, Tsou, Wari', Yapese, and Yeyi. Several of the systematized sound recordings from these languages are made available at the UCLA Phonetics Lab Archive: http://hctv.humnet.ucla.edu/departments/ linguistics/VowelsandConsonants/

\section{A CASE STUDY OF PHONETIC DOCUMENTATION: TODA LANGUAGE}

The present author has been involved in ongoing work on Toda language (phonetics as well as other areas of the language). With Prof. Ladefoged, he initially conducted phonetic fieldwork on this language and reported the outcome of the research in two collaborative papers $[34,37]$. Later, in collaboration with Prof. Tsuyoshi Nara, he continued fieldwork on this language and reported the research in three collaborative monographs [40-42]. A short description of the phonetic component of these works follows that could illustrate the tasks involved in phonetic documentation of endangered languages.

Toda is a highly endangered language. It belongs to the Dravidian family of languages and is spoken on the lofty Nilagiri mountains of South India. The Todas are about 1,000 in number - this number includes children who may not be learning and performing in the language proficiently. It is surrounded by the dominant Tamil language. A majority of the Toda speakers are bilinguals in Tamil and their mother tongue. In view of its endangeredness, we undertook work on this language; also the present author continues to work on the language.

In spite of its endangeredness, this language is fortunate enough in having besides several papers, an excellent grammar, collection of texts and songs published by Emeneau $[9,43]$. The data for all these works were collected by Emeneau during 1935-38. He collected extensive phonetic materials of Toda language transcribed by hand. However, later he realized the need for electronic recording of the materials. He mentions [9]:

"One of the major imperfections results from the lack in the 1930s of portable recording apparatus: tape-recorders were developed and became available only in the '40s. All recording had to be done at dictation, or from memory after observation. Speech at natural speed could hardly be recorded at all, or at best only in very short bursts. And listening again and again to a stretch of speech at natural speed was impossible.... Ideally, I should have returned to the Todas with modern recording equipment to 
repair this imperfection of the earlier data."

However, Emeneau's phonetic observations were very accurate. This language has some of the most interesting phonetic properties for any language in the world. It has some vowels (the front rounded vowels along with central vowels and back unrounded vowels) that are not found in any other Indian language. It has three rhotics that contrast mostly on the basis of place of articulation. In addition it distinguishes four laterals differentiated by voicing and place of articulation. There are seven voiceless fricatives in its repertoire which contrast with each other. Some of them get voiced due to morphophonemic processes and develop contrastiveness. Its plosives also contrast at seven places of articulation and voicedness giving rise to a total of fourteen stops and affricates. All these features were meticulously described by Emeneau. With this extensive information in the background, Peter Ladefoged and the present author visited the Toda area in February 1992 and made extensive recordings. Before going to the field a comprehensive word list (of about 250 words) illustrating the contrastive sounds was prepared from the available literature. In the field, we identified 6 women and 6 men as our main language consultants. Detailed high quality analog audio recordings as well as palatographic recordings of the speakers were made. The palatographic recordings were highly essential because of the fine distinction in lingual places of articulation in the language. Results of the analysis were published as reported above. A complete list of words that we used is available [44]. Copies of the recordings and further particulars can be obtained on request. Some of the illustrative words can be heard from: http://hctv.humnet. ucla.edu/departments / linguistics / VowelsandConsonants / appendix/languages/toda/toda.html

Prof. Nara and the present author continued the work on various other aspects of documentation of this language. However, there is a good amount of phonetic element in this work too. During several visits to the field, about 4,000 words were recorded on DAT tape recorders from three speakers. The sound files of these words are processed and are available. Similarly extensive spoken material from running narratives was collected and published along with the audio files on CDs. More recent field work yielded a good amount of song material which was published with transcription, gloss, cultural notes and the audio files are made available on CDs.

\section{PHONETIC DOCUMENTATION COMPONENT IN PROJECTS ON ENDANGERED LANGUAGES:}

Though there are several associations, societies and organizations conducting projects on documentation of endangered languages, two major projects could be briefly mentioned here.
The project on "Documentation of Endangered Languages (DOBES)" is a large project that has been working on documenting endangered languages throughout the world. The following passage quoted from the following web-site explains their work: http://www.mpi.nl/DOBES/ program/index.html

"The DOBES program includes a number of documentation teams (currently 20). These teams do their documentation work along the guidelines agreed upon in the DOBES program. The results of this documentation work are handed over to the archiving team (each team can of course handle copies of their data sets). This team has to take care that the archive is in a consistent state and contains data in open formats, so that those who have the rights to can access it and so that the data are stored safely."

At the following link, the project explains about the phonetic component of documentation as: "For an endangered language priority must be given to the systematic recording, transcription and translation of the broadest possible variety of spoken language samples." http://www.mpi.nl/world/DOBES/applicants/dobes-lingaspects-lang-doc.html

According to this project, among other aspects, the minimal phonetic component required for documentation includes an annotated corpus of audio-recordings and a detailed phonetic/phonological description including an inventory of segmental and prosodic phonemic distinctions and allophonic/allotonic rules. The corpus of recordings, together with their transcriptions and translations, constitute the main body of the documentation.

The Hans Rausing Endangered Languages Project (HRELP) "is intended to be a major new centre for the repository of digital data for the linguistic and social sciences." This newly started project proposes to have a substantial amount of phonetic documentation and archiving of endangered languages as explained at: http:// www.hrelp.org/arch/home.htm

\section{ARCHIVAL DOCUMENTATION AND ANALYTICAL DOCUMENTATION}

So far we have looked at the published outputs of some projects as well as the proposed components of phonetic documentation in some ongoing or nascent projects. At this juncture it would be useful to make a distinction between archival part and analytical part of documentation.

Recording the speech of a language can range from the simplest audio recording to highly systematic phonetic documentation. However, a simple recording of speech sounds as part of words, sentences or longer utterances will not be of much later use unless the recording is accompanied by good phonetic and phonemic transcription 
of it. Audio recording and transcription are done on two different media - analog or digital sound recording is the medium for audio recording whereas transcription is done on paper and could be stored as (un)formatted text files on a computer. Annotation superimposes the transcription component on the digital audio recording. The digitally recorded medium gives a powerful facility for annotation. Though a minimal amount of tagging can be done on a DAT recorder, elaborate annotation can only be done on a digital file in a computer. Several commercial softwares as well as softwares specially prepared for projects are available for annotation. The outcome of such an annotation is Archival Documentation. For instance, in the DOBES project mentioned above, one of the minimal requirements for its language documentation is an annotated corpus of audio-recordings. Ladefoged and Maddieson [7] sum up the need for archival documentation:

"Original data on endangered languages must be made as widely available as possible. This should include the text, glosses and phonetic transcription of audio recordings. Phonetic archives that have recordings with no accompanying written texts are seldom of any use. Instrumental records should also be carefully preserved, along with interpretive comments. Linguists can manage with written records of dead languages for many aspects of their work. But in phonology and phonetics we must build our theories on explicit accounts of what people do, and what they sound like. These theories often refer to notions of universality, so we must be able to provide material for as many languages as possible. If this is not done soon, the number of languages on which our ideas can be based will be severely limited."

Ladefoged's [11] "four basic tasks in making a description of the phonetic structures of language" were listed earlier. An important component of these tasks is doing and publishing an analysis of the phonetic data that was collected. He pointed out that in practice all these four components "overlap (especially the writing, which should be carried out throughout the fieldwork; it should never be left till the investigation is completed)." Elsewhere [45], he emphasized "Of course the end of data gathering is not the beginning of analysis. That should have begun long ago. Whatever kind of experiment or fieldwork you have been conducting, you should have been analyzing your data as you go." His later remarks: "After you have written everything, I hope you will publish a complete account of the work.... Private knowledge does the world no good" show the importance of analysis and its publication for a comprehensive phonetic documentation project as listed in Table 1.
Table 1 Four types of recording and documentation.

\begin{tabular}{lcccc}
\hline & $\begin{array}{c}\text { Audio } \\
\text { recording }\end{array}$ & $\begin{array}{c}\text { Phonetic } \\
\text { transcription }\end{array}$ & Annotation & Analysis \\
\hline $\begin{array}{l}\text { Audio } \\
\text { recording }\end{array}$ & + & - & - & - \\
$\begin{array}{l}\text { Phonetic } \\
\text { transcription }\end{array}$ & $(+)$ & + & - & - \\
$\begin{array}{l}\text { Archival } \\
\text { documentation }\end{array}$ & + & + & + & - \\
$\begin{array}{l}\text { Analytical } \\
\text { documentation }\end{array}$ & + & & & \\
\hline
\end{tabular}

As it is clear from the above table, analytical documentation could be considered as the most comprehensive type of documentation as it contains all the four features including a phonetic analysis of the documented material.

\section{LOGISTICS OF PHONETIC DOCUMENTATION}

Ladefoged [11], Ladefoged and Maddieson [7], and Ladefoged's most recent book [45] contain details of various essential topics such as: preparation of word lists for elicitation, qualitative and quantitative aspects of language speakers for recording, selection and use of audio recording equipment, palatographic and photographic techniques in recording places of articulation, techniques and instrumentation for aerodynamic investigations of speech sounds, recording of material for analysis of suprasegmental features such as pitch, loudness and length, acoustic analysis of vowels and consonants. A methodical fieldwork is essential for a comprehensive documentation. The above three works are the major source for all information about phonetic fieldwork and phonetic documentation. Ladefoged [45] also cautions the fieldworker about taking care of the legal obligations under 'protection of research subjects' clause in several countries. Since a fieldworker engages language speakers as research subjects, the obligations on the part of the fieldworker have to be clear in mind. Recently laws about copyright and performer's rights have become more elaborate in many countries. Though these laws might allow copying and playing of recorded material for educational and research purposes, broadcasting through internet or publishing copies of audio-visual materials (even on non-profit basis) might attract certain conditions under these laws. Care need to be taken to follow these legal conditions.

\section{SUMMARY}

The origins of phonetic documentation lie in transcription of spoken language. Such transcriptions have been of different degrees of fineness. In spite of lack of any 
instrumentation, several highly reliable phonetically transcribed materials of languages have been produced. However, an urgent need is felt for phonetic documentation of endangered languages whose speech is almost going to become extinct soon. Fortunately, we now have advanced sound recording and processing mechanisms. In addition, there are available various other recording techniques such as palatography, aerodynamics of speech that can record different kinds of speech gestures and signals. Coupled with these techniques for recording and preserving different aspects of speech sounds and realizing the urgency for phonetic documentation of endangered languages, at least one major project has produced excellent materials and research. Individual research papers and digital outputs have recorded the phonetics of some of the endangered languages. There are a couple of other projects that have different degrees of phonetic documentation as part of overall language documentation of endangered languages.

In addition to what has been produced so far, the most pressing need now is phonetic documentation of the remaining hundreds of endangered languages. This needs to be done in a systematic way as described in several of the above quoted works of Prof. Ladefoged and his colleagues before it is too late because scores of such languages are disappearing fast.

\section{REFERENCES}

[1] C. F. Hockett, A Course in Modern Linguistics (The Macmillan Co., New York, 1958).

[2] J. C. Catford, "The articulatory possibilities of man," in Manual of Phonetics, B. Malmberg, Ed. (North-Holland, Amsterdam, 1968).

[3] P. Ladefoged, Preliminaries to Linguistic Phonetics (University of Chicago Press, Chicago, 1971).

[4] K. Hale, M. Krauss, L. J. Watahomigie, A. Yamamoto, C. Craig, L. M. Jeanne and N. C. England, "Endangered languages," Language, 68, 1-42 (1992).

[5] M. Krauss, "Mass language extinction, and documentation: The race against time," Lectures on Endangered Languages: 2 - From Kyoto Conference 2000, pp. 19-39, ELPR Publication Series C002, Osaka (2001).

[6] O. Miyaoka, "Endangered languages: The crumbling of the ecosystem of language and culture - An introduction to Kyoto Conference," Lectures on Endangered Languages: 2 From Kyoto Conference 2000, pp. 3-17, ELPR Publication Series C002, Osaka (2001).

[7] P. Ladefoged and I. Maddieson, "Recording the phonetic structures of endangered languages," UCLA Work. Pap. Phonet., 93, 1-7 (1996).

[8] M. B. Emeneau, "The vowels of the Badaga language," Language, 15, 43-47 (1939).

[9] M. B. Emeneau, Toda Grammar and Texts (American Philosophical Society, Philadelphia, 1984), p. 1.

[10] P. Ladefoged and I. Maddieson, The Sounds of the World's Languages (Blackwell, Oxford, 1996) pp. 313-314.

[11] P. Ladefoged, "Instrumental techniques for linguistic phonetic fieldwork," in A Handbook of the Phonetic Sciences, W. Hardcastle and J. Laver, Eds. (Blackwell, Oxford, 1997).
[12] P. Bhaskararao and P. Ladefoged, "Two types of voiceless nasals." J. Int. Phonet. Assoc., 21, 80-88 (1991).

[13] B. Blankenship, P. Ladefoged, P. Bhaskararao and N. Chase, "Phonetic structures of Khonoma Angami," Linguist. TibetoBurman Area, 16(2), 69-88 (1993).

[14] T. Cho and P. Ladefoged, "Variations and universals in VOT: Evidence from 18 languages," J. Phonet., 27, 207-229 (1999).

[15] T. Cho, S.-A. Jun and P. Ladefoged, "An acoustic and aerodynamic study of consonants in Cheju," Korean J. Speech Sci., 7, 109-141 (2000).

[16] T. Cho, Sun-Ah Jun, Seung-Chul Jung and Peter Ladefoged, "Vowels of Cheju," Korean J. Linguist., 26, 801-819 (2001).

[17] M. Gordon, B. Potter, J. Dawson, W. de Reuse and P. Ladefoged, "Phonetic structures of Western Apache," Int. J. Am. Linguist., 67, 415-448 (2001).

[18] M. Gordon, P. Munro and P. Ladefoged, "Some phonetic structures of Chickasaw," Anthropol. Linguist., 42, 366-400 (2000).

[19] M. Gordon and P. Ladefoged, "Phonation types: a crosslinguistic review," J. Phonet., 29, 383-406 (2001).

[20] P. Ladefoged and E. Zeitoun, "Pulmonic ingressive phones do not occur in Tsou," J. Int. Phonet. Assoc., 23, 13-15 (1993).

[21] P. Ladefoged and A. Traill, "Clicks and their accompaniments," J. Phonet., 22, 33-64 (1994).

[22] P. Ladefoged, "Voiceless approximants in Tee," Festschrift for Kay Wiliamson (University of Port Harcourt Press, Port Harcourt, 1995).

[23] P. Ladefoged and D. Everett, "The status of phonetic rarities," Language, 72, 794-800 (1996).

[24] P. Ladefoged, J. Ladefoged and D. Everett, "Phonetic structures of Banawá, an endangered language," Phonetica, 54, 94-111 (1997).

[25] P. Ladefoged, J. Ladefoged, A. Turk, K. Hind and S. J. Skilton, "Phonetic structures of Scottish Gaelic, J. Int. Phonet. Assoc., 28, 1-42 (1998).

[26] P. Ladefoged and T. Cho, (2001) "Linking linguistic contrasts to reality: the case of VOT," in To Honour Eli FischerJørgensen, N. Grønnum and J. Rischel, Eds. (C. A. Reitzel, Copenhagen, 2001), pp. 212-225.

[27] I. Maddieson and P. Ladefoged. "The phonetics of partially nasal consonants," in Nasals, Nasalization and the Velum, M. K. Huffman and R. A. Krakow, Eds. (Academic Press, San Diego, 1993), pp. 251-301.

[28] I. Maddieson and S. Spajic, B. Sands and P. Ladefoged, "The phonetic structures of Dahalo," Afr. Arbeitspap., 36, 5-53 (1993).

[29] I. Maddieson and V. B. Anderson, "Some phonetic characteristics of Iaai," Proc. XIIIth Int. Congr. Phonet. Sci., 3, 540-543 (1995).

[30] I. Maddieson, P. Ladefoged and B. Sands, "Clicks in East African languages," in African Mosaic: Festschrift for J. A. Louw, R. Finlayson, Ed. (UNISA Press, Johannesburg, 1990).

[31] J. McDonough and P. Ladefoged, "The specification of stops in Navajo," in Dam Phonology, M. Nespor and N. Smith, Eds. (Holland Academic Graphics, The Hague, 1996).

[32] M. MacEachern, B. Kern and P. Ladefoged, "Wari' phonetic structures," J. Amazonian Lang., 1, 3-28.

[33] B. Sands, I. Maddieson and P. Ladefoged, "The phonetic structures of Hadza," Studies Afr. Linguist., 25, 171-204 (1996).

[34] M. Shalev, P. Ladefoged and P. Bhaskararao, "Phonetics of Toda,” PILC J. Dravidic Studies, 4, 21-56 (1994).

[35] A. Shryock, P. Ladefoged and K. Williamson, "The phonetic structures of Defaka," J. West Afr. Lang., 26(2), 3-27 (1996/7). 
[36] D. Silverman, B. Blankenship, P. Kirk and P. Ladefoged, "Phonetic structures in Jalapa Mazatec," Anthropol. Linguist., 37, 70-88 (1995).

[37] S. Spajic, P. Ladefoged and P. Bhaskararao, "The trills of Toda," J. Int. Phonet. Assoc., 26, 1-21 (1996).

[38] A. Taff, L. Rozelle, T. Cho, P. Ladefoged, M. Dirks and J. Wegelin, "Phonetic structures of Aleut," J. Phonet., 29, 231271 (2001).

[39] R. Wright and P. Ladefoged, "A phonetic study of Tsou," Bull. Inst. Hist. Philol., Acad. Sin., 68, 987-1028 (1996).

[40] T. Nara and P. Bhaskararao, Toda Vocabulary - A Preliminary List. (ELPR Series, Osaka, 2001), 208 pp.

[41] T. Nara and P. Bhaskararao, Toda Texts (ELPR Series, Osaka, 2002), 94 pp.[+CD with sound files of the texts].

[42] T. Nara and P. Bhaskararao, Songs of the Toda (ELPR Series, Osaka, 2003), 91 pp.[+3CDs with sound files of the songs].

[43] M. B. Emeneau, Toda Songs (Oxford University Press, Oxford, 1971).

[44] UCLA Working Papers in Phonetics, Vol. 84 (1993), pp. 123125.
[45] P. Ladefoged, Phonetic Data Analysis: An Introduction to Phonetic Fieldwork and Instrumental Techniques (Blackwell, Oxford, 2003).

Peri Bhaskararao is a Professor of Linguistics at the Research Institute for Languages and Cultures of Asia and Africa, Tokyo University of Foreign Studies, Tokyo. The academic degrees that he received are: (from Andhra University, India) 1964- Bachelor of Science, 1966- Master of Arts in Sanskrit Language; (from Pune University, India) 1968- Master of Arts in Linguistics, 1973- Doctor of Philosophy in Linguistics. Before leaving India in 1993 for Tokyo, he worked as Professor of Phonetics at Deccan College, Pune, India. His major area of interest is phonetics including both its articulatory and acoustic aspects with a special emphasis on systematic accumulation and analysis of empirical linguistic-phonetic data for creation of a speech knowledge-base. Such a speech knowledge-base is very useful in creating systems for man-machine interaction. 